\title{
The physiological and pathophysiological aspects of the maxillary sinus
}

\author{
Manish Munjal ${ }^{1 *}$, Ritu Gupta ${ }^{1}$, Joginder Sidhu², Shubham Munjal², \\ Sahil Ahluwalia', Mehak Bath', Archit Pal Singh'
}

${ }^{1}$ Department of ENTHNS, ${ }^{2}$ Department of Physiology, Dayanand Medical College, Ludhiana, Punjab, India

\author{
Received: 28 July 2020 \\ Revised: 09 September 2020 \\ Accepted: 11 September 2020 \\ *Correspondence: \\ Dr. Manish Munjal, \\ E-mail: manishmunjaldr@yahoo.com
}

Copyright: (C) the author(s), publisher and licensee Medip Academy. This is an open-access article distributed under the terms of the Creative Commons Attribution Non-Commercial License, which permits unrestricted non-commercial use, distribution, and reproduction in any medium, provided the original work is properly cited.

\begin{abstract}
Among the paranasal sinuses the maxillary sinus with a bottle neck ventilatory and drainage pathway is the commonest sinus to be involved in inflammatory pathologies. With limited intervention at the osteo-meatal unit the disturbed intricate mucociliary physiology of the sinus tends to revert. The surgery being aptly captioned, the "functional endoscopic sinus surgery". The unique physio-pathology of the maxillary sinus shall be elaborated.
\end{abstract}

Keywords: Maxillary sinus, Physiology, Pathology

\section{INTRODUCTION}

The maxillary sinus with its antigravity muco-ciliary clearance escalator is likely to retain the secretions so produced by its lining. The sinus ostium if effected, alters the sinus ventilation as well as its drainage. The physiology and pathophysiology of the maxillary sinus needs introspection.

\section{REVIEW OF LITERATURE}

\section{Physiological aspects}

The maxillary sinus is lined by ciliated columnar epithelium with the highest density of goblet cells compared to the other paranasal sinuses (median $9: 700 / \mathrm{mm}^{2}$ ). The sero mucinous glands are relatively infrequent but are maximum in the maxillary sinus and concentrated around the ostium. ${ }^{1}$

In the maxillary sinus, transportation of secretions begins from the floor of the sinus in a stellate pattern. The mucus is then carried along the medial anterior, lateral and posterior walls of the sinus and along the roof to converge at the natural ostium of the maxillary sinus (Figure 1). The natural ostium typically opens into the floor of the posterior third of the ethmoidal infundibulum, which opens into the middle meatus through the hiatus semilunaris. The mucus is transported via the infundibulum through the hiatus semilunaris, over the medial face of the inferior turbinate posteriorly into the nasopharynx. ${ }^{2}$

Secretions from the maxillary sinus are always transported via the natural ostium, even when one or more accessory ostia exist in the area of the nasal fontanelles and even in those patients in whom a patent window in the inferior meatus has been surgically created. Although an inferior meatal naso-antral window may ventilate a diseased sinus to revert the lining of the sinus, it cannot achieve sufficient active outwardly directed transportation of mucus. ${ }^{2}$

Accessory ostia frequently present in the fontanelles of the maxillary sinus are usually by passed by the normal secretion pathways. Due to higher viscosity, the entire mucus layer may move over such an accessory ostium without any mucus escaping from the sinus. ${ }^{2}$ The sinus requires a patent ostium and a healthy lining mucosa. 
Healthy mucosa means normally functioning cilia and mucus secretion of normal viscosity and elasticity. Ventilation prevents sinus hypoxia and avoids subsequent transudation of serous fluid, ciliary dysfunction and mucus gland dysfunction as documented by Pinhero et al. ${ }^{3}$ The cilia beat in a synchronized fashion, with only the tips propelling the gel phase during their active beat, and remain within the sol phase during recovery, thereby propelling the gel phase during their active beat. The beat frequency ranges from $8-20$ beats per second by Stammberger. ${ }^{4}$

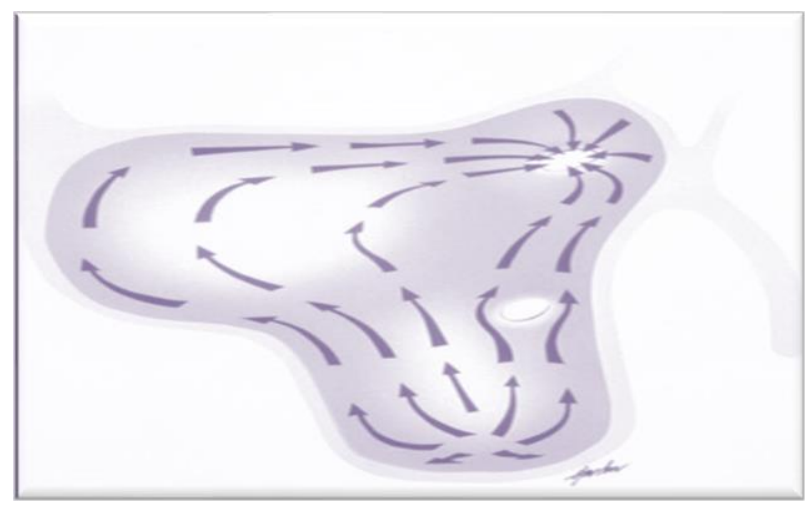

Figure 1: Schematic representation of ciliary beat of the right maxillary sinus.

\section{Pathophysiological aspects}

Any pathology in the sinuses is due to abnormal mucociliary flow resulting from alteration in the normal ventilation or drainage of the sinuses.

In the pathogenesis of sinus pathology, the presence of "mucosal contact areas" is the single most important factor by suggested Messerklinger. ${ }^{12}$ Various etiologies are responsible for the obstruction of the mucociliary drainage pathway. Narrowing of the maxillary sinus drainage pathway at any of its surroundings, due to mucosal oedema polyps scarring and adhesions secondary to trauma infection or previous surgery may lead to obstruction by Levine and May. ${ }^{5}$

\section{ETIOLOGICAL/PREDISPOSING FACTORS FOR MAXILLARY SINUSITIS}

According to Mackay and Lund, four etiological/predisposing factors are responsible for maxillary sinusitis: anatomical variants, mucociliary abnormalities, immune deficiency, and allergy.

Mucociliary abnormalities can be primary (primary ciliary dyskinesia, cystic fibrosis, Young's syndrome) and secondary (allergy and bacterial infection). Mucociliary clearance can be impaired by hypoxia temperature variations, dehydration medications (antihistamines and anticholinergics), and cigarette smoke, foreign bodies, infections, environmental irritants, trauma and tumours.
Immune deficiency, which may be primary or idiopathic type and the secondary type due to human immunodeficiency virus (HIV) infection or being on immunosuppressant drugs. ${ }^{4}$

More than $90 \%$ of frontal and maxillary sinusitis is due to pathology in the anterior ethmoid region and limited surgery to treat these distal sites can re-establish ventilation and drainage. The non-invasive assessment of the maxillary sinus pathology has been carried out using plane radiography.

In Water's or occipitomental view, the maxillary antra are clearly visible. In Caldwell's or occipitofrontal view, the upper portion of the antra is obscured by the petrous bones but their lower parts are visualized. On the lateral projection, the paired sinuses are superimposed on each other, but the extent of pneumatisation of the sinuses can be assessed. $^{7}$ Role of sinus radiographs is very controversial with false positive and false negative interpretations. Normal sinuses are radiolucent, whereas pathological sinuses exhibit varying grades of opacity or air fluid level. ${ }^{8}$ Infact, sinus radiographs are not reliable in clinical decisions and did not accurately imply presence of disease of the sinuses and their drainage pathways because of overlapping structures by Lazar et al, Goldstein and Philips. ${ }^{9,10}$

In horizontal beam $5^{\circ}$ off-lateral view, the patient's head is positioned laterally relative to the cassette, and the nose is then rotated $5^{\circ}$ toward the cassette from the true lateral position. If the patient is seated, the cassette is usually placed in the vertical position. If the patient is lying down in either the semi prone or the prone position, the cassette is positioned horizontally. The central ray enters perpendicular to the cassette and is centred at the outer canthus of the eye in the middle of the film. ${ }^{11,12}$ The orbitomeatal line is parallel to the base of the film. The purpose of using the $5^{\circ}$ off-lateral view rather than the true lateral view is to rotate the posterior walls of the maxillary antra slightly so that they do not superimpose on one another. This permits individual evaluation of the integrity of the posterior antral bony margins. ${ }^{13}$

Pathological processes of the paranasal sinuses encroach on the air in the sinuses and are seen on the radiographs as alterations in the translucency of the sinus. Examination in the erect position is ideal to detect air fluid levels. In asymmetrical paired sinuses the smaller sinus appears more opaque due its thicker bony walls. Antra differ in size less often, though small differences are not uncommon. ${ }^{7}$

\section{Computed tomography $(\mathrm{CT})$ and magnetic resonance imaging (MRI) of the maxillary sinus}

CT and MRI are the preferred modalities to delineate pathology in the maxillary sinus and potential malignancies. Aarteriography is reserved for the vascular pathologies. Typically malignancies erode bone, whereas 
benign processes cause reactive thickening or remodelling of adjacent bone.

\section{Maxillary sinus pathology}

In adults, the maxillary sinuses are commonly affected with acute and chronic sinusitis. The patient with acute maxillary sinusitis presents with pain over the cheek which may radiate into the frontal region or the dentition, which classically exacerbates with straining or bending down. Specific localizing signs are not always present as one sinus alone is rarely affected, and there may be diffuse discomfort from pansinusitis. A degree of tenderness may be present over the maxillary sinus. Significant tenderness and oedema might suggest a dental abscess or incipient complications. The nasal mucosa is swollen particularly in the region of middle meatus. ${ }^{14}$ Acute sinusitis commonly results from secondary bacterial invasion after viral rhinitis. The viruses most frequently implicated are rhino, corona, influenza and parainfluenza viruses. Typically, viral infection leads to swelling of the mucosal lining of nose and sinuses, blockage of the sinus ostia, interference with the clearance mechanisms and stasis. ${ }^{14}$

Scott showed that viruses produce mucus degrading enzymes, neuraminidases, which loosen the mucus and promote rapid virus diffusion through the sol layer of the mucociliary blanket. ${ }^{15}$ These viruses, therefore, avoid clearance in the gel layer and are capable of rapid adherence to the epithelium and incorporation into the epithelial cells. These factors favour secondary infection by the multitude of potentially pathogenic bacteria which are resident on the flora of the nose and pharynx. Once bacterial infection supervenes, a number of common pathogens are found especially Streptococcus pneumoniae and Haemophilus influenza, which account for $>50 \%$ of proven maxillary infection. However, a range of organisms can be found even in the acute situation, including anaerobes. ${ }^{14}$ In 1996, the American academy of otolaryngology-head and neck surgery convened a multidisciplinary rhino sinusitis task force (RTF). This group defined adult rhino sinusitis diagnostic criteria. In 2003, this definition was amended to require confirmatory radiographic or nasal endoscopic or physical examination findings in addition to suggestive history. ${ }^{16}$

\section{CONCLUSION}

On vis a vis the physiology and pathophysiology of the maxillary sinus ideally limited, surgical intervention is undertaken in sinusitis, at the osteo-meatal unit to facilitate drainage and ventilation of the maxillary sinus and thereby revert till now inactive mucociliary clearance.

Funding: No funding sources Conflict of interest: None declared Ethical approval: Not required

\section{REFERENCES}

1. Stammberger H, Lund VJ. Anatomy of the nose and paranasal sinuses. In Michael Gleeson, editor. Scott Brown's Otorhinolaryngology, head and neck surgery. 7th ed. London: Elsevier. 2008;1341.

2. Stammberger H, Hawke M. Basic Principles of Functional Endoscopic Sinus Surgery. In. Essentials of Endoscopic Sinus Surgery. Mosby. 1993;2.

3. Pinhero AD, Facer GW, Kern EB. Sinusitis. Current concepts and management. In Bailey BJ (Ed): Head and Neck Surgery-Otolaryngology, Ed Philadelphia, Lippincott-Raven. 1998;441.

4. Stammberger H. Functional Endoscopic Sinus Surgery. Philadelphia, DC Becker. 1991;432-3.

5. Levine HL, May M. Endoscopic Sinus Surgery. New York. Thieme Medical Publishers. 1993;4-13.

6. Mackay IS, Lund VJ. Surgical management of sinusitis. Scott Brown's Otolaryngology, 6th ed. Butterworth Hienemann, Oxford. 1997.

7. Phelps PD. Radiology of the Nose and Paranasal Sinuses. In: Mackay and Bull, editors. Scott Brown's Otorhinolaryngology, Head and Neck Surgery. 6th ed. London: Elsevier. 1997;4.

8. Gray H. Carter HV. Nose, nasal cavity and paranasal sinuses. In: Gray's Anatomy The anatomical basis of clinical practice. 37th ed. London. 1993.

9. Lazar RH, Younis RT, Long TE. Functional endoscopic sinus surgery in adults and children. Laryngoscope. 1993;103:1-5.

10. Goldstein JH, Philips CD. Current indications and techniques in evaluating inflammatory disease and neoplasia of the Sino nasal cavities. Curr Probl Diagn Radio. 1998;27:41-71.

11. Yousem DM. Imaging of sin nasal inflammatory disease. Radiolology. 1993;188(2):303-4.

12. Messerklinger W. Endoscopy of the nose. Baltimore, Maryland, Urban and Schwarzenberg.1978;49.

13. Weed DT, Cole RR. Maxillary sinus hypoplasia and vertical dystopia of the orbit. Laryngoscope. 1994;104:758-62.

14. Weir N, Golding-Wood DG. Infective rhinitis and sinusitis. In: Mackay and Bull, editors. Scott Brown's Otorhinolaryngology, Head and Neck Surgery. 6th ed. London. Elsevier. 1997;4(8):18-9.

15. Scott GM. How do viruses overcome mucosal defences? In: Bacterial and Viral Inhibition and Modulation of Host Defences, edited by Falcone G, Campa M, Smith H, Scott GM. London Academic Press. 1984;25-39.

16. Patel A. American Academy of Otolaryngology, Bulletin. 1999;18(2).

Cite this article as: Munjal M, Gupta R, Sidhu J, Munjal S, Ahluwalia S, Bath M, Singh AP. The physiological and pathophysiological aspects of the maxillary sinus. Int $\mathbf{J}$ Otorhinolaryngol Head Neck Surg 2020;6:2160-2. 